\title{
Correction to: Propagation and establishment of rupestrian grassland grasses for restoration of degraded areas by mining
}

\author{
Maurilio Assis Figueiredo ${ }^{1}$ (1) Adriana Pedrosa Diniz ${ }^{1} \cdot$ Maria Cristina Teixeira Braga Messias $^{2}$. \\ Alessandra Rodrigues Kozovits ${ }^{2}$
}

Published online: 14 June 2018

(C) Botanical Society of Sao Paulo 2018

\section{Correction to: Brazilian Journal of Botany https://doi.org/10.1007/s40415-018-0456-x}

The layout of Table 1 was incorrect in the PDF version of the initial online publication. The original article has been corrected.

The original article can be found online at https:// doi.org/10.1007/s40415-018-0456-x.

Maurilio Assis Figueiredo maurilioafigueiredo@gmail.com;

maurilioafigueiredo@ufop.edu.br

1 Department of Geology, Federal University of Ouro Preto, Campus Morro do Cruzeiro, Ouro Preto, Minas Gerais CEP 35400-000, Brazil

2 Department of Biodiversity, Evolution and Environment, Federal University of Ouro Preto, Campus Morro do Cruzeiro, Ouro Preto, Minas Gerais CEP 35400-000, Brazil 